\title{
Nickel Subsulfide
}

National Cancer Institute

\section{Source}

National Cancer Institute. Nickel Subsulfide. NCI Thesaurus. Code C29841.

Exposure to inorganic carcinogenic Nickel Subsulfide, an atmospheric pollutant primarily generated by industries that manufacture lithium batteries, results in inflammation, hyperplasia, and fibrosis in the lungs and olfactory epithelium. (NCI04) 